\title{
Análise de desempenho dos modelos de previsão de insolvência e a implementação das Normas Internacionais de Contabilidade
}

\author{
Analysis of performance of forecast models insolvency and the implementation \\ of International Accounting Standards
}

\author{
Jefferson Pereira Andrade ${ }^{1}$ \\ Wenner Glaucio Lopes Lucena²
}

\begin{abstract}
Resumo
O objetivo deste estudo consiste em verificar a capacidade de predição dos principais modelos de insolvência desenvolvidos no Brasil observando a implementação das normas internacionais de contabilidade. Foram analisados oito modelos previsão: Elizabetsky (1976); Kanitz (1978); Altman, Baidya e Dias (1979); Matias (1979); Silva (1982); Kasznar (1986); Sanvicente e Minardi (1998) e Scarpel (2000). A pesquisa foi desenvolvida com 17 empresas que apresentaram problemas financeiros no período de 2004 a 2015, sendo coletados dados dessas empresas por meio do site da Bovespa e na base de dados Economática®. Após a análise, chegou-se àsseguintes conclusões: apenas dois modelos tiveram alto grau de acertos em suas previsões, ou seja, apenas dois deles foram capazes de prever a insolvência, sendo eles os modelos de Elisabetsky (1976) e Sanvicente e Misardi (1998).Já os modelos de Kanitz (1978) e Kasznar (1986) tiveram os piores desempenhos na previsão da insolvência. Quanto à adoção das normas internacionais de contabilidade, verificou-se que, em cinco modelos, a precisão foi maior nas empresas que emitiram demonstrativos baseados nas normas internacionais. Entretanto, não se pode afirmar que os resultados são influenciados diretamente pelas normas internacionais.
\end{abstract}

Palavras-chave: Demonstrações Contábeis; Modelos de Previsão; Insolvência; Normas Internacionais de Contabilidade.

\begin{abstract}
The purpose of this study is to verify the capacity of prediction of the main models of insolvency developed in Brazil observing the implementation of international accounting standards. Eight predictive models were analyzed, Elizabetsky (1976); Kanitz (1978); Altman, Baidya and Dias (1979); Matias (1979); Silva (1982); Kasznar (1986); Sanvicente and Minardi (1998) and Scarpel (2000). The research was developed with 17 companies that presented financial problems in the period from 2004 to 2015, data were collected from these companies through the Bovespa website and the Economática ${ }^{\circledR}$ data base.After the analysis the following conclusions were reached: only two models had a high degree of correctness in their predictions being able to predict insolvency, the models of Elisabetsky (1976) and Sanvicente and Misardi (1998) presented the best results in relation to Moreover, the models of Kanitz (1978) and Kasznar (1986) had the worst performances in predicting insolvency. Regarding the adoption of international accounting standards, it was verified that in five models the accuracy was higher in companies that issued statements based on international standards, however it can not be said that results are influenced directly by international standards.
\end{abstract}

Keywords: Financial Statements; Models Forecasting; Insolvency; International Accounting Standards.

\section{Introdução}

As organizações são criadas objetivando lucratividade contínua, entretanto, nos últimos anos,boa parte das empresas não conseguiu alcançar essa continuidade. Segundo dados do Serasa Exprerian

1 Mestrando em Ciências Contábeis pela Universidade Federal de Paraíba (UFPB). Brasil. Afiliação: UFPB. Lattes: http://lattes.cnpq. br/4165751768692757 Email: pereira_jp2008@hotmail.com

2 Doutorado em Ciências Contábeis pela Universidade de Brasília(UnB). Brasil. Afiliação: UFPB. Lattes: http://lattes.cnpq.br/8131572207239842 Email: wdlucena@yahoo.com.br 
(2015), apenas no mês de maio de 2015 houve um aumento de $53,2 \%$ no número de empresas que foram decretadas como falidas em comparação com o mesmo período do ano anterior.

Segundo Altman, Baidya e Dias (1979), períodos de instabilidade financeira fazem parte de todas as empresas, o que implica que, cedo ou tarde, uma empresa irá passar por problemas financeiros que podem levar a sua descontinuidade. Determinar as variáveis que possuem correlação com o fracasso empresarial é, sem dúvida, imprescindível, mas outra questão de extrema importância diz respeito à capacidade de prevê-la. Identificar os indícios de insolvências pode fornecer a entidade tempo hábil para que sejam tomadas decisões que signifiquem um novo recomeço para a organização.

Segundo Rodrigues Junior, Silva e Hein (2012), nenhuma empresa vai da ascensão ao declínio de um dia para o outro, esse é um processo gradual, o que torna possível a sua previsão. Ao longo dos anos, diversos teóricos têm discutido essa possibilidade e desenvolvido modelos matemáticos visando, principalmente, à análise do risco de crédito. A principal ideia nessa linha de pesquisa é buscar identificar entre as empresas falidas características comuns que possibilitem perceber tendência a desequilíbrios financeiros.

Em 1966, Beaver fez o primeiro uso de técnicas estatísticas objetivando a previsão de solvência. Ele reuniu uma amostra de 79 empresas solventes e 79 empresas insolventes que foram submetidas a uma análise dicotômica que permitiu ao pesquisador definir um ponto crítico para a classificação das empresas em solventes e insolventes (MARIO, 2002).

Após o trabalho de Beaver, motivado pela não existência de bases teóricas para a análise financeira, Altman desenvolveu um dos primeiros modelos estatísticos visando à análise de insolvência a partir da técnica de análise descriminante (ALTMAN, 1968). Tanto Altman como Beaver são tidos como percussores internacionais com relação à previsão de insolvência em nível mundial.

No Brasil, o primeiro registro de trabalho envolvendo a análise de solvência ocorreu por iniciativa de Kanitz, em 1974. Posteriormente, inúmeros outros autores desenvolveram estudos nessa linha pesquisa, como Elizabetsky (1976); Altman, Baidya e Dias (1979); Matias (1978); Silva (1982); Kasznan (1986); Sanvicente e Misardi (1998); Scarpel (2000).

Esses modelos partem, em sua maioria, de informações extraídas das demonstrações contábeis, os chamados indicadores contábeis, e são baseados na premissa de que essas demonstrações são capazes de revelar a situação financeira e econômica das empresas que as emitem. Segundo Scarpel (2000), foi devido à necessidade prática existente no mercado de crédito de se avaliar o grau de solvência e determinar o risco das empresas tomadoras de empréstimos que surgiu a análise baseada em indicadores contábeis.

Um dos grandes limitadores desse tipo de estudo é o fato de resultarem em uma ou mais equações responsáveis por evidenciar a situação em que as empresas se encontram, essa equação apresenta-se de forma universal, sem considerar as organizações com organismos sujeita a mudanças econômicas, normativas e operacionais.

Recentemente, alterações normativas (A Conversão as Normas Internacionais de Contabilidade) têm provocado mudanças na contabilidade mundial, base de muitos modelos de previsão, colocando em dúvida a utilidade desses modelos e reacendendo a dúvida existente com relação ao seu desempenho.

Diante da fragilidade exposta acima em relação aos modelos de insolvência e às mudanças contábeis ocorridas no Brasil,coloca-se a seguinte questão de pesquisa: Qual é a capacidade de predição dos principais modelos de previsão de insolvência desenvolvidos no Brasil, no período de 2004 a 2015, tomando como base a configuração(implementação) das normas internacionais de contabilidade?

O presente trabalho objetiva verificar a capacidade de predição dos principais modelos de previsão de falência desenvolvidos no Brasil, no período de 2004 a 2015, considerando a implementação das normas internacionais de contabilidade.

O presente estudo se justifica pelo fato das empresas fornecerem mais do que apenas retornos financeiros. Elas desempenham um papel fundamental dentro da sociedade. De acordo com Espinosa (2013), essa característica torna a continuidade empresarial um fato de interesse da sociedade como um todo. Dessa forma, os diagnósticos fornecidos pelos modelos têm sua importância alavancada e constituem um importante instrumento de diagnostico que desemboca em ações corretivas capazes de determinar o futuro das organizações (ALMEIDA; CARVALHO; ALMEIDA, 2016). 


\section{Modelos de Previsão de Insolvência}

A análise financeira e econômica de uma empresa tem por base os dados gerados internamente por ela através da sua contabilidade e apresentados na forma de indicadores contábeis. Os indicadores contábeis, por sua vez, consistem em índices responsáveis por apontar determinada posição da entidade e que, quando analisados em conjunto, irão proporcionar uma visão geral da situação financeira da empresa para seus analistas. Historicamente, o uso de indicadores financeiros teve início no século XX, tendo os primeiros indicadores desenvolvido por Alexander Wall, em 1919 (PEREIRA,2008).

Nos dias atuais, segundo Capobiango et al. (2012), os indicadores financeiros podem ser divididos em quatro grupos: Índices de Liquidez; Índices de endividamento; Índices de Lucratividade e Índices de Atividade. A utilidade de cada indicador está atrelada aos objetivos, experiência e visão de cada analista. Cada usuário da informação contábil, seja ele interno,seja externo, possui um interesse particular nas organizações. Consequentemente, o conjunto de indicadores usados na análise econômica irá variar entre eles.

Com relação aos processos administrativos, os indicadores contribuem de forma significativa na gestão das empresas. Para Dominguez, Garcia e Barraza (2014), esse interesse se dá pelo fato de que os gestores precisam saber a situação financeira da sua empresa e necessitam continuamente analisar os progressos dos negócios e controlá-los através da utilização desse tipo de ferramenta.

As condições de mercado e as decisões tomadas pela cúpula administrativa de uma empresa frequentemente causam impactos na sua situação financeira, podendo causar desequilíbrios temporários, ou permanentes. Segundo as prerrogativas contábeis, esses desajustes são evidenciados nas demonstrações contábeis e, consequentemente, refletidos nos indicadores. De acordo com Troacã (2013), dentre todos os indicadores, a solvência ocupa um lugar central na análise financeira devido a sua capacidade de refletir as possibilidades de uma empresa honrar suas dívidas atuais e de longo prazo.

Com base nesses indicadores, desde o início do século passado foram desenvolvidos estudos almejando predizer a insolvência empresarial.Entretanto, esses estudos só ganharam rigor cientifico a partir dos anos de 1930, com os trabalhos de autores como Fitzpatrick (1932) e Winakor e Smith (1935), e foi só nos anos 1970, a partir dos trabalhos de Beaver (1966) e Altman (1968), que ganharam um rigor estatístico mais apurado (CANPILLO; SERER; FERRER, 2013). Para Pinheiro et al. (2007), os trabalhos de Beaver (1966) e Altman (1968) foram precursores internacionais na utilização de técnicas estatísticas no desenvolvimento de modelos de insolvência com a utilização de técnicas univariadas e multivariadas.

No Brasil, o professor Stefhen Chales Kanitz, em 1974, enquanto era responsável pela elaboração da lista das quinhentas maiores e melhores empresas brasileiras da revista Exame, desenvolveu o primeiro estudo de previsão de solvência brasileiro, que ficou conhecido como fator de insolvência ou termômetro de Kanitz (KASSAI; KASSAI, 1998). Posteriormente, foram desenvolvidos diversos outros estudos, dentre os quais se destacam Elizabetsky (1976); Altman, Baidya e Dias (1979); Matias (1978); Silva(1982); Kasznan (1986); Sanvicente e Misardi (1998) e Scarpel (2000). Esses modelos são os mais citados quando o assunto é previsão de insolvência no Brasil e constituem a base da investigação do presente trabalho, sendo apresentados no quadro a seguir.

Quadro 01 - Principais modelos de previsão desenvolvidos no Brasil.

\begin{tabular}{|c|c|c|}
\hline Modelo & Equação & Variáveis \\
\hline \multirow{6}{*}{ Elizabetsky } & \multirow{6}{*}{$\begin{array}{l}Z=1,93 \times 1-0,20 \times 2+1,02 \times 3+ \\
1,33 \times 4-1,12 \times 5\end{array}$} & $Z=$ Total de pontos obtidos \\
\hline & & X1 = lucro líquido / vendas \\
\hline & & X2 = disponível / ativo permanente \\
\hline & & $\mathrm{X} 3=$ contas a receber $/$ ativo total \\
\hline & & $\mathrm{X} 4$ = estoque $/$ ativo total \\
\hline & & X5 = passivo circulante / ativo total \\
\hline
\end{tabular}


Continuação

\begin{tabular}{|c|c|c|}
\hline \multirow{6}{*}{ Kanitz } & \multirow{6}{*}{$\begin{array}{l}\mathrm{FI}=0,05 \times 1+1,65 \times 2+3,55 \times 3- \\
1,06 \times 4-0,33 \times 5\end{array}$} & $\mathrm{FI}=$ Fator de Insolvência \\
\hline & & X1 = Lucro Líquido / Patrimônio Líquido \\
\hline & & $\begin{array}{l}\text { X2 = (Ativo Circulante + Realizável a Longo Prazo }) / \\
\text { Exigível total }\end{array}$ \\
\hline & & $\begin{array}{l}\text { X3 = (Ativo Circulante - Estoques) / Passivo } \\
\text { Circulante }\end{array}$ \\
\hline & & X4 = Ativo Circulante / Passivo Circulante \\
\hline & & X5 = Exigível total / Patrimônio Líquido \\
\hline \multirow{5}{*}{$\begin{array}{l}\text { Altiman, } \\
\text { Baidya e } \\
\text { Dias }\end{array}$} & \multirow{5}{*}{$\begin{array}{l}Z 1=-1,44+4,03 \times 2+2,25 X 3+0,14 \\
X 4+0,42 \times 5\end{array}$} & $\mathrm{Z1}=$ Total de pontos obtidos \\
\hline & & $\begin{array}{l}\mathrm{X} 2=\text { (Não exigível }- \text { capital aportado pelos acionistas) } \\
\text { / Ativo total }\end{array}$ \\
\hline & & X3= Lucros antes dos juros e impostos / Ativo Total \\
\hline & & X4= Patrimônio líquido / Exigível total \\
\hline & & X5= Vendas $/$ Ativo Total \\
\hline \multirow{7}{*}{ Matias } & \multirow{7}{*}{$\begin{array}{l}Z=23,792 \times 1-8,26 \times 2-9,868 \times 3- \\
0,764 \times 4-0,535 \times 5 \\
+9,912 \times 6\end{array}$} & $Z=$ Total dos pontos obtidos \\
\hline & & X1 = Patrimônio líquido / Ativo total \\
\hline & & $\begin{array}{l}\text { X2 = Financiamento e empréstimos bancários / Ativo } \\
\text { circulante }\end{array}$ \\
\hline & & X3 = Fornecedores / Ativo Total \\
\hline & & X4 = Ativo Circulante / Passivo circulante \\
\hline & & X5 = Lucro operacional / lucro bruto \\
\hline & & X6 = Disponível / Ativo total \\
\hline \multirow{11}{*}{$\begin{array}{l}\text { Silva para } \\
\text { empresas } \\
\text { comerciais }\end{array}$} & & Z1 = Total de pontos obtidos \\
\hline & \multirow{9}{*}{$\begin{array}{l}Z 1=0,722-5,124 Y 1+11,016 Y 2- \\
0,342 Y 3-0,048 Y 4 \\
+8,605 Y 5-0,004 Y 6\end{array}$} & Y1 = Duplicatas descontadas / duplicatas a receber \\
\hline & & $\begin{array}{l}\text { Y2 = Estoques (final) / Custo das mercadorias } \\
\text { vendidas }\end{array}$ \\
\hline & & Y3 = Fornecedores $/$ Vendas \\
\hline & & $\begin{array}{l}\text { Y4 }=(\text { Estoque médio/Custo das mercadorias } \\
\text { vendidas }) \times 360\end{array}$ \\
\hline & & $\begin{array}{l}\text { Y5 }=(\text { Lucro operacional }+ \text { Desp. financeiras }) / \\
\text { (Ativo total }- \text { Investimento Médio) }\end{array}$ \\
\hline & & $\begin{array}{l}\text { Y6 = Exigível Total /(Lucro líquido + 0,1 Imobilizado } \\
\text { Médio + Saldo Devedor da Correção }\end{array}$ \\
\hline & & Monetária). \\
\hline & & $\mathrm{Z} 2=$ Total de pontos obtidos \\
\hline & & X1 = Reservas + Lucros Acumulados / Ativo Total \\
\hline & & X2 = Disponível / Ativo Total \\
\hline \multirow{4}{*}{$\begin{array}{l}\text { Silva para } \\
\text { empresas } \\
\text { industriais }\end{array}$} & \multirow{4}{*}{$\begin{array}{l}Z 2=-1,327+7,561 X 1+8,201 X 2 \\
-8,546 X 3+4,218 X 4+1,982 X 5+ \\
0,091 X 6\end{array}$} & $\begin{array}{l}\text { X3 = Ativo Circulante - Disponível - Passivo } \\
\text { Circulante + Financiamentos Bancários + Duplicatas } \\
\text { Descontadas / Vendas }\end{array}$ \\
\hline & & $\begin{array}{l}\text { X4 = Lucro Operacional + Despesas Financeiras / } \\
\text { Ativo Total Médio - investimento Médio }\end{array}$ \\
\hline & & X5 = Lucro Operacional / lucro bruto \\
\hline & & $\begin{array}{l}\text { X6 = (Patrimônio Líquido / Passivo Circulante + } \\
\text { Exigível a Longo Prazo) / (Lucro Bruto * } 100 / \text { vendas) } \\
\text { / (Prazo Médio de Rotação de Estoques + Prazo } \\
\text { Médio de Recebimento de Vendas - Prazo Médio de } \\
\text { Pagamento de Compras) }\end{array}$ \\
\hline
\end{tabular}


Continuação

\begin{tabular}{|c|c|c|}
\hline \multirow{6}{*}{ Kasznar } & \multirow{6}{*}{$\begin{array}{l}Z=0,28 X 1+0,17 X 2+0,19 \times 3+0,08 \\
X 4+0,43 \times 5\end{array}$} & $Z=$ Total de pontos obtidos \\
\hline & & X1= Capital de Giro/ Ativo Total \\
\hline & & X2= Capital não exigível total líquido/ Ativo Total \\
\hline & & $\mathrm{X} 3=$ Lucro Antes dos Impostos e Juros / Ativo Total \\
\hline & & $\begin{array}{l}\text { X4= Valor de Mercado da Participação Acionaria e } \\
\text { das Ações Preferenciais/ Passivo Total }\end{array}$ \\
\hline & & X5 $=$ Vendas Líquidas / Ativos Totais \\
\hline \multirow{6}{*}{$\begin{array}{l}\text { Sanvicente } \\
\text { e Minardi }\end{array}$} & \multirow{6}{*}{$\begin{array}{l}Z=-0,042+2,909 \times 1-0,875 \times 2+ \\
3,636 \times 3+0,172 X 4+0,029 \times 8\end{array}$} & $Z=$ Total de pontos obtidos \\
\hline & & $\mathrm{X} 1=$ (ativo circulante - passivo total) $/$ ativo total \\
\hline & & $\mathrm{X} 2=$ (patrimônio líquido - capital social) / ativo total \\
\hline & & $\begin{array}{l}X 3=\text { (lucro operacional }- \text { despesas financeiras }+ \\
\text { receitas financeiras) / ativo total }\end{array}$ \\
\hline & & $\begin{array}{l}\text { X4= valor contábil do patrimônio líquido / valor } \\
\text { contábil do exigível total }\end{array}$ \\
\hline & & $\begin{array}{l}X 8=\text { lucro operacional antes de juros e imposto de } \\
\text { renda / despesas financeiras }\end{array}$ \\
\hline \multirow{4}{*}{ Scarpel } & \multirow{4}{*}{$P_{i}=\frac{1}{1+\mathrm{e}^{\left(-\left(0,190+3,312 \mathrm{GA}_{\mathrm{i}}-3,687 \mathrm{EG}_{\mathrm{i}}+10,997 \mathrm{ROAAAIR}_{\mathrm{i}}\right)\right)}}$} & $\mathrm{Pi}=$ Total de pontos obtidos \\
\hline & & $\mathrm{GA}=$ Giro total do ativo \\
\hline & & $\mathrm{EG}=$ Índice de endividamento geral \\
\hline & & $\begin{array}{l}\text { ROA AJIR= Retorno sobre o ativo antes de juros e } \\
\text { imposto de renda }\end{array}$ \\
\hline
\end{tabular}

Fonte: Baseado em Nobre e Lima (2014); Kassai e Kassai (1998); Kanitz (1978); Altiman, Baidya e Dias (1979); Soares, Shumacher e Lopes (2011); Dalmoro et al. (2012); Pinheiro et al. (2007); Kasznar (1986); Sanvicente e Minardi (1998) e Scarpel (2000).

Cada modelo resulta em uma equação e um ponto crítico, ou intervalo, utilizado para classificação das empresas como solvente ou insolvente. Para os modelos de Elizabetsky e Scarpel, o ponto crítico é definido como 0,5 . Valores acima desse ponto correspondem à solvência e vice-versa, valores abaixo representam a insolvência. Enquanto isso, o modelo de Kanitz, diferentemente dos outros modelos, não possui um único ponto crítico. Ele pode assumir valores entre -7 a 7 , em que os resultados que se encontram entre 7 e 0 atribuem a condição de solvente a empresa. Já os resultados entre -1 e -3 são considerados como penumbra, isso é, o resultado é inconclusivo. Mas, mesmo assim, essa situação inspira cuidado. Entre -4 e -7 as empresas encontram-se insolventes.

Os modelos de Altiman, Baidya e Dias; Matias; Silva e Sanvicente e Minardi têm o ponto crítico de definido como 0 . Dessa forma, valores abaixo do ponto crítico são tidos como insolventes, enquanto valores acima desse valor são classificados como solventes. Já para o modelo de Kasznar são consideradas solventes as empresas com $Z \geq 1,4$, e insolentes as empresas com $Z \leq-1,6$. Valores localizados entre $-1,6$ e $+1,4$ são imprecisos e inconclusivos.

\section{Convergência as Normas Internacionais}

Antes das International Financial Reporting Standards - IFRS, as práticas contábeis divergiam entre os países. No ano de 2005, a União Europeia passou a adotar um único regime contábil que, mais tarde, diversos outros países viriam a adotar. Atualmente,aproximadamente 170 países adotam essas normas. Entretanto, Lourenço e Branco (2015) destacam o fato de grandes potências econômicas mundiais, como os Estados Unidos, o Japão e a Índia,ainda não terem aderido.

O Brasil passou a adotar as normas internacionais a parti da Lei 11.638 de 2007, que tornou obrigatória a observância para empresas de grande porte e para as sociedades anônimas. Segundo Araújo et al. (2014),o 
processo de conversão no Brasil também se deu pela institucionalização do Comitê de Pronunciamentos Contábeis - CPC, responsável pela emissão de forma centralizada das novas normas contábeis.

A efetiva implementação das IFRS se deu em duas etapas:a primeira delas em 2008, com a Lei 11.638/07 e os documentos emitidos pelo CPC, válidos para 2008; já a segunda fase é resultante dos Pronunciamentos Técnicos emitidos pelo CPC válido para 2010, (GRECCO, 2013). Desse modo, a implementação da convergência pode ser classificada em três momentos distintos: Pré- IFRS, que acorreu até 2007; híbrido entre os BR GAAP (Do inglês Generally Accepted Accounting Principles) e IFRS, ocorrida no período de 2008 e 2009; e Pós-IFRS ocorrida a parti do ano de 2010 (GRECCO, 2013).

Como resultado, o novo padrão contábil provocou inúmeras alterações na maneira de reconhecer, mensurar e evidenciar um elemento patrimonial, provocando alteração na representação financeira das empresas, além de prováveis mudanças na qualidade e utilidade dos dados utilizados (FARIAS ET AL., 2014).

Diversas pesquisas já evidenciaram os impactos dessas mudanças na informação divulgada, como Lourenço e Branco (2015), que verificaram uma melhoria na qualidade e relevância do resultado líquido de empresas que sinalizaram boas práticas de governança corporativa. Machado, Silva Filho e Callado (2014) detectaram um aumento da capacidade explicativa do lucro líquido e do fluxo de caixa operacional combinado com os accruals quando calculados pelo enfoque do fluxo de caixa. Farias et. al. (2014) constataram a redução de indicadores de liquidez de bancos listados na BM \& FBOVESPA quando comparados com as demonstrações de acordo com IFRS e BR GAAP. Grecco (2013) não encontrou divergência quanto ao nível de gerenciamento de resultados antes e depois das IFRS nas companhias abertas brasileiras não financeiras.

\section{Metodologia}

A presente pesquisa caracteriza-se, quanto aos objetivos, como descritiva, o que, para Gil (2012), como o próprio nome sugere, descreve determinado fenômeno, característica de uma população, ou ainda estabelece relações entre variáveis.

Quanto aos procedimentos,classifica-se como bibliográfica, que consiste em levantar toda a biografia escrita acerca do tema,sendo desenvolvida em quatro etapas: identificação, localização, compilação e fichamento das fontes de informação (MEDEIROS, 2012). Ainda quanto aos procedimentos, caracteriza-se com documental, pois faz uso de fontes que não sofreram qualquer análise científica (MEDEIROS, 2012).

Quanto à abordagem, caracteriza-se como quantitativa. Segundo Michel (2009), é aquela que parte do princípio de que todas as coisas são quantificáveis, ou podem ser traduzidas, na forma de números. Esses números, por sua vez, são submetidos a diversas técnicas estatísticas para, assim, chegar a conclusões.

O horizonte temporal no qual se desenvolveu o estudo compreende o período de 2004 a 2015, visto que a conversão as IFRS se deu parcialmente a partir de 2008, e de forma efetiva em 2010, definindo um período de 6 anos pré-IFRS e 6 anos pós-IFRS.

A população objeto dessa pesquisa é formada por empresas de capital aberto listadas na Bovespa que enfrentaram problemas financeiros entre 2004 e 2015, correspondendo a um total de 29 empresas. A amostra foi constituída conforme indicação da figura a seguir.

\section{Universo de 29 empresas}

\section{(-) 9 empresas com dados indisponíveis}

(-) 3 empresas com dados faltosos

Amostra de 17 empresas

Figura 1 - Formação da Amostra

Fonte: Dados da pesquisa (2016). 
Dentre as empresas da população, não foram localizadas as informações financeiras de nove delas, sendo eliminadas da amostra. Três delas também foram eliminadas devido a alguns dados faltosos. Dessa maneira, chegou-se a uma amostra de 17 empresas, que corresponde a um total de 58,62\% da população.

Todos os dados necessários para aplicação dos modelos foram coletados através das demonstrações financeiras das empresas (Balanço, demonstração do resultado do exercício e notas explicativas) disponíveis no site da Bovespa e na base de dados Economatica ${ }^{\circledR}$. Uma vez que os modelos são desenvolvidos buscando a identificação da situação financeira um ano antes da constatação dos problemas financeiros, os dados correspondem às demonstrações contábeis anuais imediatamente anteriores à data da petição inicial de recuperação, ou da concordata, feita pela empresa. Caso esse período correspondesse a intervalo inferior a seis meses, foram coletadas informações referente às demonstrações intermediárias, anteriores as demonstrações anuais. Após a coleta dos dados, foram aplicados todos os modelos em estudo, e os resultados foram demonstrados através da estatística descritiva.

\section{Análise dos dados}

\subsection{Análise das empresas em recuperação judicial}

Inicialmente,para a análise dos dados, é importante conhecer as empresas que compõem a amostra analisada. A tabela 1, a seguir, apresenta quais são essas empresas e as datas em que entraram com o pedido de recuperação judicial, além do tipo de atividade que exercem, uma vez que alguns dos modelos são desenvolvidos a partir do tipo de atividade.

Tabela 1 - Empresas em recuperação judicial

\begin{tabular}{lcc}
\hline Empresas & Data do pedido de recuperação & Atividade \\
\hline Sansuy S.A. Indústria De Plásticos & $20 / 12 / 2005$ & Indústria e comércio \\
Eucatex S.A. Indústria E Comercio & $16 / 08 / 2005$ & Indústria e comércio \\
Recrusul S.A. & $25 / 01 / 2006$ & Indústria e comércio \\
Agrenco Ltd. & $27 / 08 / 2008$ & Comércio \\
Construtora Beter S.A. & $12 / 09 / 2008$ & Serviços \\
Ceramica Chiarelli S.A. & $30 / 12 / 2008$ & Indústria e comércio \\
Igb Eletrônica S/A & $30 / 12 / 2008$ & Indústria e comércio \\
Fiacao Tec Sao Jose S.A. & $12 / 07 / 2010$ & Indústria e comercio \\
Rede Energia S. A. & $23 / 11 / 2012$ & Holding \\
Teka- Tecelagem Kuehnrich S.A. & $26 / 10 / 2012$ & Indústria \\
Clarion S/A Agroindustrial & $05 / 06 / 2013$ & Holding \\
Mangels Industrial S. A. & $01 / 11 / 2013$ & Indústria \\
Osx Brasil S.A. & $11 / 11 / 2013$ & Indústria \\
Eneva S.A & $09 / 12 / 2014$ & Indústria \\
Fibam Companhia Industrial & $14 / 10 / 2014$ & Indústria \\
Inepar S.A. Indústria e Construções & $29 / 08 / 2014$ & Indústria \\
Lupatech S.A. & $13 / 12 / 2014$ & Indústria e comércio \\
\hline
\end{tabular}

Fonte: Dados da pesquisa (2016).

O maior número de pedidos de recuperação judicial entre as empresas na amostra foi feito nos anos de 2008 e 2014, e as empresas atuantes no setor da indústria foram a maioria delas. A amostra ainda apresenta 2 holdings e uma empresa de serviços.

Os anos de 2007, 2009 e 2011 não tiveram nenhuma representante na amostra analisada, além do ano de 2015. Oito delas tiveram suas demonstrações coletadas enquanto ainda não vigorava as normas internacionais, já as outras apresentavam demonstrações de acordo com a convergência.

A tabela 2 traz características financeiras das empresas evidenciadas em suas demonstrações financeiras um ano antes do pedido de recuperação judicial. 
Tabela 2 - Caracterização das empresas $\mathrm{R} \$ 1,00$

\begin{tabular}{lcccc}
\hline Variável & Mínimo & Máximo & Média & Desvio padrão \\
\hline Patrimônio Líquido & -870.456 & 19.708 .975 & 15.700 .485 & 480.586 \\
Capital Social & 7.000 & 45.322 .313 & 5.595 .235 & 14.482 .412 \\
Lucro líquido & -21.013 .745 & 2.123 & -1.417 .406 & 5.057 .015 \\
\hline
\end{tabular}

Fonte: Dados da pesquisa (2016).

Segundo Macro e Kapp (2013), uma das características de uma empresa insolvente é patrimônio líquido negativo, que foi apresentada em $41,18 \%$ das empresas analisadas. Os valores do patrimônio líquido estão distribuídos entre $\mathrm{R} \$-870.458,00$ e $\mathrm{R} \$ 19.708 .975,00$. Em média, o patrimônio líquido das empresas é $\mathrm{R} \$ 1.570 .485,00$, com desvio padrão de $\mathrm{R} \$ 4.805 .286,57$.

O capital social dessas empresas está concentrado $95 \%$ entre $R \$ 0,00$ e $R \$ 10.000 .000,00$, com média de $R \$ 5.595 .235,24$ e desvio padrão de $\mathrm{R} \$ 14.482 .412,29$. O menor valor do capital social é o da empresa TEKA - Tecelagem Kuehnrich S/A, correspondendo a $R \$ 7.000,00$, e o maior é o da empresa Enerva S/A, com um capital social de $\mathrm{R} \$ 45.322 .314,00$.

Outro fator condicionante do insucesso empresarial é um longo histórico de prejuízos. Por esse motivo, o lucro líquido do período também foi evidenciado na tabela 2. Dentre todas as empresas, apenas uma não apresentou prejuízo em suas demonstrações financeiras antes do pedido de concordata/ recuperação judicial. O maior prejuízo foi apurado pela Construtora Better S/A, equivalente a $R \$-21.013 .745,0$. Os resultados médios apurados giram em torno de $\mathrm{R} \$-1.417 .406,88$, com desvio padrão de $\mathrm{R} \$ 5.057 .015,445$.

\subsection{Análise dos modelos}

Nesta seção são apresentados os resultados da aplicação dos modelos de previsão de insolvência apresentados na revisão da literatura.

O modelo de Elizabetsky tem como ponto de corte 0,05 (KASSAI E KASSAI, 1998). As empresas com valores abaixo desse valor apresentam problemas financeiros, implicando que todos os resultados acima deveriam ser inferiores a 0,05.

De acordo com a quadro 2(apresentado no apêndice 01), das 17 empresas a que foi aplicado o modelo de Elizabetsky, apenas uma apresentou valor superior a 0,05 , chegando a uma precisão de $94,11 \%$. Considerando a classificação como pré e pós-IFRS, o modelo conseguiu prever os problemas financeiros de todas as empresas no período pré-IFRS, enquanto depois da convergência apenas para uma empresa, a FIBIAM, não foi possível prever os problemas financeiros.

Quanto aos resultados do modelo de Kanitz, apenas uma empresa foi caracterizada como insolvente, pois o resultado do termômetro assumiu valor inferior a -4 . Duas empresas apresentaram resultados que configuraram imprecisão no modelo, e as demais empresas foram classificadas como solventes. Percentualmente, os resultados podem ser assim descritos: $82,35 \%$ encontram-se na faixa de solvência, $11,76 \%$ encontram-se na faixa de imprecisão e apenas 5,88\% apresentam-se como insolventes.

O ponto crítico do modelo de Altmam, Baidya e Dias é definido como 0.Dessa forma, empresas com tendência a problemas financeiros deveriam apresentar o valor de $z<0$. Quatro empresas, dentre as analisadas, equivalente a $23,52 \%$, apresentaram-se como solventes e $76,48 \%$ das empresas apresentaram $z<0$, conferindo a qualidade de insolvência a essas empresas. Desse modo, determina-se que o percentual de acerto do modelo foi de $76,47 \%$. Quando analisado em períodos pré e pós-convergência, nas empresas do primeiro grupo, a predição foi em torno de $63 \%$, enquanto para o segundo grupo essa precisão chegou em torno de88\%.

Assim como o modelo de Altman, Baidya e Dias, o ponto crítico do modelo de Matias é 0 . De acordo com os resultados obtidos e descriminados no quadro 2, oito das 17 empresas apresentaram $Z$ maior que zero, correspondendo a 47,05\%; nove empresas apresentaram Z menor que zero, caracterizando o percentual de acerto do modelo como $52,95 \%$. Dentre as empresas cujas demonstrações foram elaboradas 
conforme as normas internacionais, quatro demonstraram a incapacidade preditiva do modelo no primeiro grupo, enquanto no segundo a incapacidade de precisão correspondeu a quatro de oito.

Outro modelo aqui analisado foi o de Silva, que, como mencionado na fundamentação teórica do trabalho, resultou em duas equações:uma para empresas industriais e outra para empresas comerciais.

Tanto para empresas industriais como comerciais, o ponto crítico é definido como 0.Entretanto,os dois modelos foram aplicados em todas as empresas, inclusive na Construtora Better S/A, que é do setor de serviços, e nas empresas Rede Energia S/A e Clarion S/A Agroindustrial, que são holdings. Em todas essas empresas os modelos, tanto o comercial como o industrial, conseguiram prever a insolvência.

A Rede Energia possui participação em empresas do ramo de distribuição de energia elétrica, o que reflete características comerciais em suas demonstrações, e a Clarion S/AAgroindústria possui participação em empresas de atacado e varejo.

Para definição dos percentuais de acerto no modelo de Silva,foi desconsiderada a aplicação nas empresas Agrenco, Rede Energia e Clarion. Desse modo, o modelo 1apresentou precisão de 60\%. Já para o modelo 02 , foi desconsiderada apenas a empresa Teka, de serviços, prevendo 56,25\% da amostra válida.

Percebe-se que, no caso das empresas cujas demonstrações foram coletadas antes de 2010 , o modelo 01 conseguiu prever 4 dentre 7 empresas, considerando a exclusão da empresa Agrenco.No segundo momento, depois de 2010, o modelo prévio incluiu 5 dentre 8 empresas, excluída a empresa Clarion S/A Agroindustrial. Já o modelo 2, antes do período de convergência, acertou 2 de 8, ou 25\%; enquanto acertou 7 de 8 após a convergência, desconsiderando a empresa Teka.

O modelo de Kasznar assume que as empresas insolventes possuem $z<-1,65$ e as solventes $z<$ 1,4, e que valores dentro do intervalo aberto $-1,65$ a 1,4 são classificados dentro da área de imprecisão do modelo. O modelo não apresentou sinal de insolvência para nenhuma das empresas, de forma que todos os resultados apontaram as empresas como solventes $(35,29 \%)$ ou que não foi possível determinar sua situação $(64,61 \%)$. O maior número de erros ocorreu antes da IFRS, e as imprecisões em ambos os períodos correspondem respectivamente a $37,5 \%$ e33,33\%.

O modelo de Sanvicente e Minardi, cujo ponto crítico é 0, apresentou precisão de $94,11 \%$, o que implica que, dentre as 17 empresas analisadas, 16 apresentarão resultado menor que zero. Verificou-se apenas uma previsão errada, tanto no período pré- IFRS quanto no período pós- IFRS. Assim, a capacidade preditiva dos modelos foide, respectivamente, $87,5 \%$ e $88,9 \%$.

Scarpel estabeleceu o valor de 0,05 como seu ponto de referência para a classificação das empresas como solvente e insolvente. Desse modo, a correta classificação das empresas acima exigiria um valor de $\mathrm{Pi}$ inferior a esse valor para todas as empresas.

De acordo com os resultados obtidos, 9 empresas apresentaram $\mathrm{Pi}>0,05$, o que as lhes conferiu a qualidade de solvente, e 8 empresas apresentaram $\mathrm{Pi}<0,05$, representando $47,05 \%$ de acertos. No período pré-convergência, o modelo foi capaz de prever corretamente a insolvência em apenas três das oito empresas. No período pós-convergência, a previsão estava correta em três das nove.

Analisados os resultados de forma individual, passa-se agora a analisar o desempenho comparado dos modelos, apresentado no gráfico 1 , a seguir.

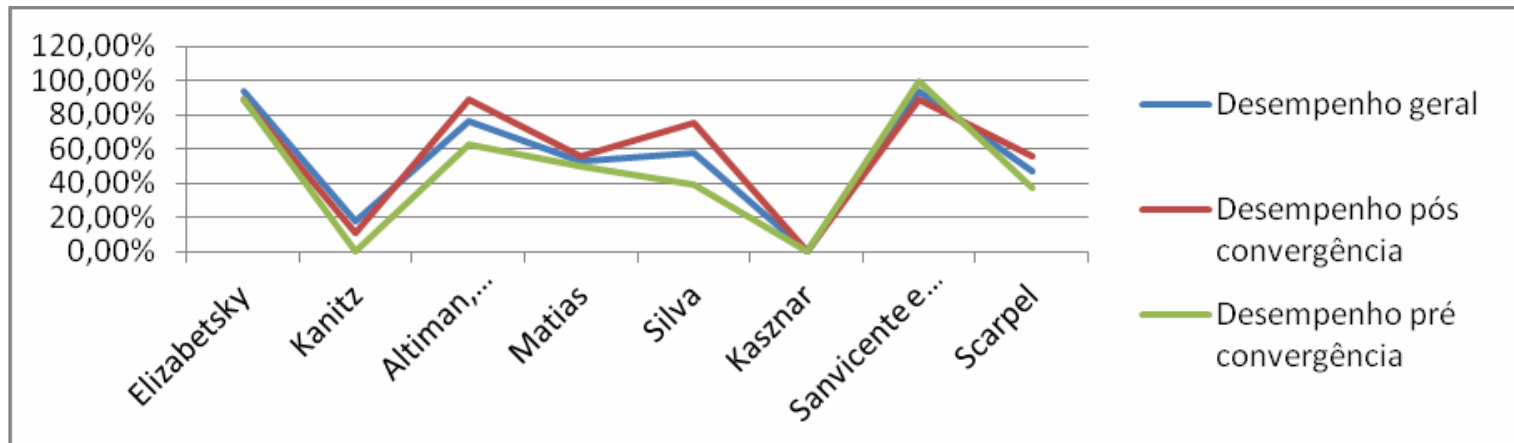

Gráfico 1 - Resultado geral dos modelos

Fonte: Dados da pesquisa (2016). 
Nota-se que o desempenho dos modelos é bastante semelhante em ambos os casos, isto é, tanto antes como depois das IFRS. Os trabalhos de Elizabetsky e Sanvicente e Misardi demonstraram ter o melhor desempenho. Esse resultado é consistente com o resultado de Pinheiro et al. (2007), efetuado com 79 empresas solventes e insolventes. Em seu estudo, o modelo de Elizabetsky obteve o melhor resultado na previsão de insolvência entre o período de 1995 a 2006, com 100\% de acertos. Já no estudo de Silva el al. (2012), realizado com 13 empresas, entre 1997 e 2003, o modelo com melhor percentual de acerto foi o de Altman, Baidya e Dias, com 100\%, seguido por Elizabetsky e Silva.

O modelo de Altman, Baidya e Dias também apresentou bom desempenho na previsão e demonstrou melhor resultado no período de 2010 a 2015, enquanto todos os demais tiveram precisão inferior a $60 \%$.

Ainda de acordo com o gráfico 1 , os modelos de pior desempenho foram os modelos de Kanitz e Kasznar, com $17,64 \%$ e $0 \%$ de acertos respectivamente. Kanitz também teve o pior desempenho no trabalho de Pinheiro et el. (2007) e Silva etal. (2012). Um fator comum entre os dois modelos reside no fato de que ambos apresentam uma região de imprecisão, o que sugere uma fragilidade nos modelos.

De forma geral, os resultados por período variaram de modelo para modelo.Quatro deles apresentaram desempenho inferior após as normas internacionais e cinco deles apresentaram melhor desempenho após a convergência. Entretanto, não se pode atribuir o desempenho do modelo como resultante da convergência para as normas internacionais.

\section{Conclusão}

O objetivo do presente trabalho consistiu em verificar a capacidade de predição dos principais modelos de previsão de falência desenvolvidos no Brasil, no período de 2004 a 2015, considerando a implementação das normas internacionais de contabilidade.

Verificou-se que os modelos apresentam variações em sua capacidade de predição ao longo dos anos. Trabalhos como Pinheiro et al. (2007) e Silva et al. (2012) corroboram com a ideia, uma vez que seus resultados demonstram divergências no grau de precisão desses modelos ao longo dos anos. Entretanto, percebe-se que alguns modelos apresentaram alto grau de predição no período analisado, sendo eles os modelos de Elizabetsky e o de Sanvicente e Minardi, com aproximadamente $94 \%$ de acertos. Cada um dos modelos classificou apenas uma empresa errada. Eo caso do modelo de Elizabetsky, a empresa foi a Fibam Cia Industrial;já para o modelo de Sanvicente e Minardi, a única empresa classificada errada foi a Enerva S.A.O modelo de Altman, Baidya e Dias, apesar de se destacar com relação aos outros (aproximadamente $76 \%$ ), também apresentou grande erro na estimativa (24\%), não sendo eficiente na previsão da insolvência.

Os modelos de Elysabetsky, Sanvicente e Minardi, e Altman, Baidya e Dias demonstraram ser os modelos de melhor resultado entre os analisados, tanto no período de 2004 a 2015, como no período de 2010 a 2015 (período de convergência as normas internacionais de contabilidade). Porém,observou-se que, no período pós-IRFS, alguns modelos, como o de Altman, Baidya e Dias e o de Silva, tiveram seus resultados aumentados no período de convergência com relação ao período total analisado. Quanto aos modelos de Kanitz e Kasznar, tiveram os piores desempenhos entre todos os modelos analisados. Uma característica em comum dos modelos é o intervalor de imprecisão, que é, no modelo de Kanitz, denominado de penumbra.

Os resultados aqui encontrados contribuem demonstrando que os modelos de Elysabetsky e de Sanvicente e Minardi são uma boa ferramenta de previsão e gestão. Para a ciência contábil, traz como contribuição a ideia de que, apesar de terem sido desenvolvidos há algumas décadas, alguns desses modelos ainda são capazes de prever a insolvência, assim como que alguns desses modelos apresentaram resultados diferentes nos períodos de pré e pós-convergência para as normas internacionais.

A pesquisa apresenta como limitação a impossibilidade de generalização dos resultados devido ao fato de terem sido coletadas informações de empresas diferentes para o estudo do desempenho antes e depois das normas internacionais. Recomenda-se, em pesquisas futuras, a utilização de uma amostra composta de empresas que não estão com problemas financeiros, além de uma busca por outras características capazes de afetar o desempenho desses modelos. 


\section{Referências}

ALMEIDA, Bruno José Machado de; CARVALHO, Pedro Miguel Torres; ALMEIDA, José Joaquim Marques de. Uma aplicação do Z-Score. Revista Ciências Administrativas, Fortaleza, v. 22, n. 1, p. 11-41, jan/jun. 2016. Disponível em <http://periodicos.unifor.br/rca/article/view/4439/pdf> Acessado em junho de 2016.

ALTMAN, Edward I. Financial ratios, discriminant analysis and the prediction of corporate bankruptcy. The journal of finance, n. 4, v. 23, setembro, 1968.

ALTMAN, Edward I; BAIDYA, Tara K. N.; DIAS, Luiz Manuel Ribeiro. Previsão de problemas financeiros em empresas. Revista de administração de empresas, Rio de Janeiro, v. 19, n.1, p. 17-28, jan/mar., 1979.

ARAÚJO, Kleber Domingos de; et al. Percepção dos impactos da adoção das IFRS na contabilidade gerencial sob a ótica os professores de programas de pós- graduação stricto sensu em contabilidade. Revista Universo Contábil. Blumenau, v. 10, n. 2, p. 105-124, abr./jun., 2014. Disponível em <www. furb.br/universocontabil>. Acessado em agosto de 2014.

BOVESPA. Bolsa de Valores de São Paulo. Disponível em< http://www.bmfbovespa.com.br/pt_br/ produtos/listados-a-vista-e-derivativos/renda- variavel/acoes/informacoes-por-periodo/>. Acessado em dezembro de 2015.

BRASIL. Lei 11.638 de 28 de dezembro de 2007. Altera e revoga dispositivos da Lei no 6.404 , de 15 de dezembro de 1976, e da Lei no 6.385, de 7 de dezembro de 1976, e estende às sociedades de grande porte disposições relativas à elaboração e divulgação de demonstrações financeiras. Brasília, 2008. Disponível em < http://www.planalto.gov.br/ccivil_03/_ato2007-2010/2007/lei//11638.htm> acessado em agosto de 2015.

CAMPILLO,José Pozuelo; SERER, Gregorio Labatut; FERRER, Ernesto Veres. Validez de la información financiera en los procesos de insolvência: Un estudio de la pequeña empresa española. Cuadernos de economía y dirección de la empresa, v 16, p. 29-40, 2013. Disponível em < http://dx.doi.org/10.1016/j. cede.2012.05.001>. Acessado em junho de 2015

CAPOBIANGO, Ronan Pereira; et al. Desempenho financeiro: Um estudo com empresas de três setores. Revista de C. humanas, Viçosa, v. 12, n. 1, p. 165-180, jan/jun., 2012.

DALMORO, Tais; et al. Aplicação dos modelos de previsão de insolvência, nas empresas da BM\&FBovespa que se encontram em situação de recuperação judicial In: Congresso de Iniciação Científica em Contabilidade da USP,10, São Paulo, 25 e 26 de junho de 2013. Anais... São Paulo: USP, 2013.

DOMÍNGUEZ, Deyanira Bernal; GARCÍA, María Luisa Saavedra; BARRAZA,Lydia María López. Financial analysis management of companies in a region of mexico: the need of a financial ratios annual directory. Review of economics \& finance, p.64- 78, 2014.

ESPINOSA, Fredy Romero. Alcances y limitaciones de los modelos de capacidad predictiva em el análisis del fracaso empresarial. AD-minister medellín-colombia, n. 23, p. 45 - 70, jul/dez., 2013.

FARIAS, José Barbosa de; et al. Impactos da adoção das IFRS nas demonstrações consolidadas dos bancos listados na BM\&FBOVESPA. Revista Universo Contábil, Blumenau, v. 10, n. 2, p. 63-83, abr./ jun., 2014. Disponível em < www.furb.br/universocontabil>. Acessado em agosto de 2015.

GIL, Antonio Carlos. Métodos e técnicas de pesquisa social. São Paulo: Atlas, 2012.

GRECCO, Marta Cristina Pelucio. O Efeito da convergência brasileira às IFRS no gerenciamento de resultados das empresas abertas brasileiras não financeiras. Brazilian Business Review, Vitória, v. 10, n. 4, p. 117 - 140, out.-dez. 2013. Disponível em < www.bbronline.com.br>. Acessado em agosto de 2015. 
KASZNAR, Istvan Karoly. Falência e concordata de empresas modelo teóricos e estudos empíricos. 1986. 225 f. Dissertação (Mestrado em economia) - Fundação Getúlio Vargas, Rio de Janeiro, 1986.

KASSAI, José Roberto; KASSAI, Silvia. Desvendando o termômetro de solvência de Kanitz In.: Congresso ENANPAD, 1998. Anais... Foz do Iguaçu: 1998. Disponível em <http://www.anpad.org.br/ diversos/trabalhos/EnANPAD/enanpad_1998/CCG/19 98_CCG8.pdf>. Acessado em julho de 2015.

LOURENÇO, Isabel Costa; BRANCO, Manuel Castelo. A governança corporativa e o efeito da adoção das IFRS: O caso brasileiro. Revista Universo Contábil, Blumenau, v. 11, n. 1, jan/mar., 2015.

Disponível em <www.furb.br/universocontabil>. Acessado em agosto de 2015.

MACHADO, Márcio André Veras; SILVA FILHO, Augusto Cezar da Cunha; CALLADO, Aldo Leonardo Cunha. O processo de convergência às IFRS e a capacidade do lucro e do fluxo de caixa em prever os fluxos de caixa futuro: Evidências no mercado brasileiro. Revista de Contabilidade e Organizações. v. 21, p. 5-13, 2014. Disponível em <www.rco.usp.br>. Acessado em agosto de 2015.

MAGRO, Luiz Caetano; KAPP, Claudio Junior. Proposta de um modelo de Previsão de falência em uma instituição financeira da região dos Campos Gerais no estado do Paraná In.: Congresso Internacional de Administração, 2013. Anais... Ponta Grossa: 2013.

MÁRIO, Poueri do Carmo. Contribuição ao estudo da solvência empresarial: Um modelo de previsão - estudo exploratório aplicado a empresas mineradoras. Dissertação (Mestrado em Controladoria e Contabilidade) - Universidade de São Paulo, São Paulo, 2002.

MEDEIROS, João Bosco. Redação Científica: A prática de fichamentos, resumos, resenhas. $11^{\mathrm{a}}$ Ed. São Paulo: Atlas, 2012.

MICHEL, Maria Helena. Metodologia e pesquisas científicas em ciênciassociais ed - São Paulo: Atlas, 2009.

NOBRE, Fábio Chaves; LIMA, Elaine Maelly Cunha de. Análise de solvência de empresas do segmento calçadista listadas no BM\&FBOVESPA. Revista De Administração e Negócios da Amazônia, vol. 6, n. 3, 2014.

PEREIRA, Vinícius Silva. A utilização de indicadores de desempenho e o valor de mercado de sociedades anônimas: Uma análise de empresas norte e latino americanas.23 de janeiro de 2008. 233 f. Dissertação (Mestrado em Administração)Universidade Federal de Uberlândia. Uberlândia, 2008.

PINHEIRO, Laura Edith Taboada; et al. Validação de Modelos Brasileiro de Previsão de Insolvência. Contabilidade Vista \& Revista, v. 18, n. 4, p. 83-103, out/ dez, 2007.

RODRIGUES JUNIOR, Moacir Manoel; SILVA, Tarcisio Pedro da; HEIN, Nelson. O uso do índice de força relativa em indicadores financeiros: Um estudo sobre a previsão de insolvência de empresas In.: XXXII Encontro Nacional De Engenharia De Produção, Bento Gonçalves, 2012. Anais... Bento Gonçalves: 2012.

SANVICENTE, Antônio Zoratto; MINARDI, Andrea Maria A. F. Identificação de indicadores contábeis significativos para previsão de concordata de empresas. Outubro de 1998.

SCARPEL, Rodrigo Arnaldo. Modelos matemáticos em análise financeira de empresas, de setores industriais e de crédito. 2000. 115 f. Dissertação (Mestrado em Ciências no curso de Engenharia Aeronáutica e Mecânica na área de organização Industrial) - Instituto tecnológico de Aeronáutica. São José dos Campos, São Paulo, 2000.

SERASA EXPERIAN. Indicador Serasa Experian de Falências e Recuperações. Disponível em <http:// www.serasaexperian.com.br/release/indicadores/falencias_concordatas.htm>. Acessado em junho de 2015.

SILVA, Júlio Orestes da; et al. Capacidade Preditiva de Modelos de Insolvência com Base em Números Contábeis e Dados Descritivos. REPeC, Brasília, v. 6, n. 3, art. 2, p. 246-261, jul/set. 2012. Disponível 
em < http://www.repec.org.br/index.php/repec/article/view/268>. Acessado em agosto de 2015.

SOARES, Cristiano Sausen; SCHUMACHER, Luci Ines; LOPES, Taize de Andrade Machado. Insolvência ou solvência? Um estudo comparativo entre empresas com diferente situação econômico financeira In.: $4^{\circ}$ Congresso UFSC de Finanças e Contabilidade, Florianópolis. Anais eletrônicos, 2011. Anais... Florianópolis: UFSC, 2011. Disponível em < http://dvl.ccn.ufsc.br/congresso/ anais/4CCF/20110112123400.pdf>. Acessado em agosto de 2015.

TROACĂ, Victor. Models for Analyzing the Business Solvency under Economic Crisis Conditions. Journal of Knowledge Management, Economics and Information Technology, dezembro de 2013. Disponível em< www.scientificpapers.org>. Acessado em junho de 2015. 

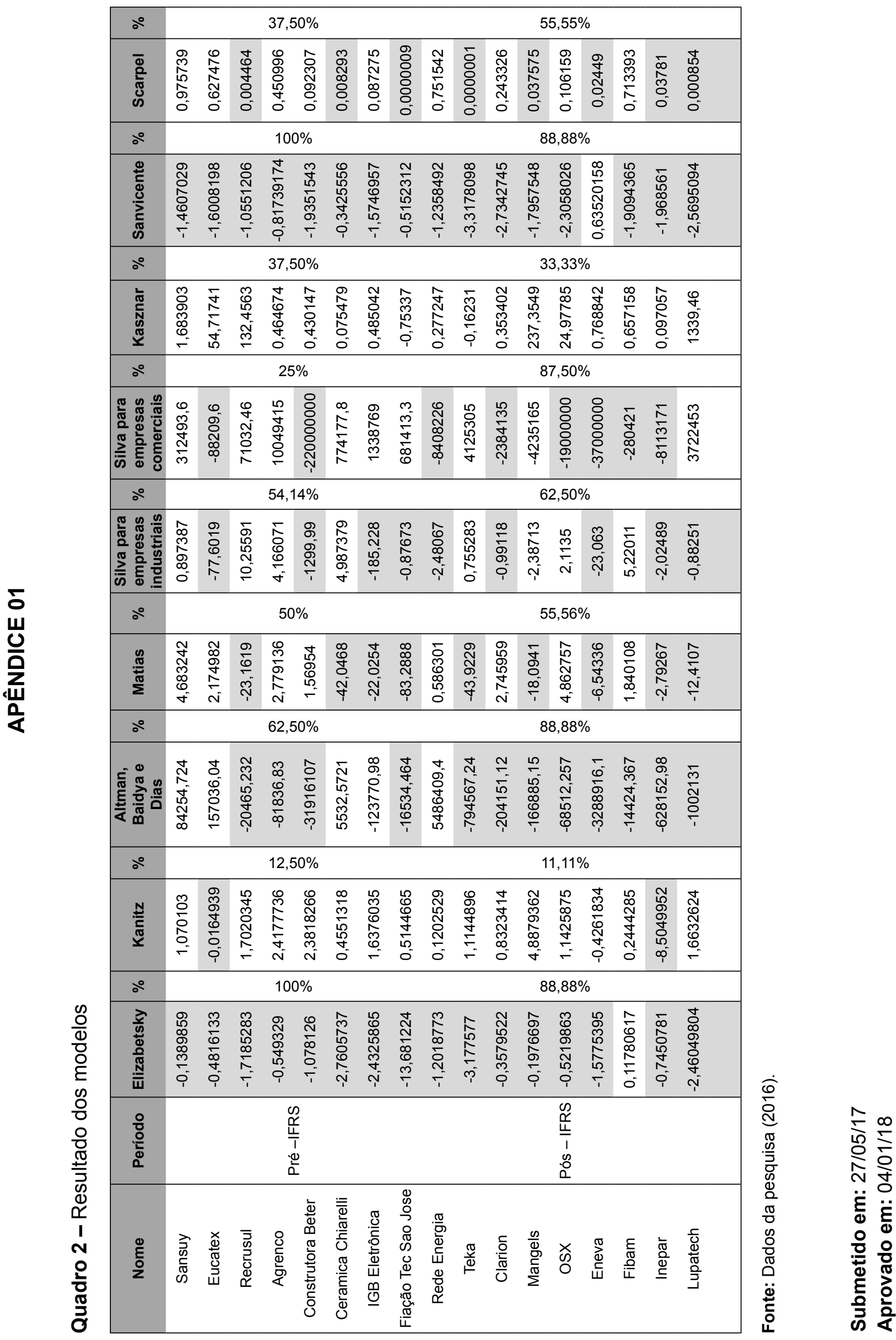